\title{
Theoretical Studies of Geometries of Hexafluoro-1,3-butadiene, Tetrafluoro-1,3-butadiene, and Difluoro-1,3-butadiene Compounds
}

\author{
Han-Gook Cho, Kang-Woo Kim, and Byeong-Seo Cheong* \\ Department of Chemistry, Eniversitv of Incheon, Incheon 402-749. Korea \\ Received June 11, 2003
}

\begin{abstract}
The geometrical stnictures of various isomers of hexafluoro-1.3-butadiene (HFBD). tetrafluoro-1.3-butadiene (TFBD), and difluoro-1.3-butadiene (DFBD) have been studied theoretically. Natural steric and natural resonance theory (NRT) analyses indicate that the lower energy of skew s-cis conformer of hexafluoro-1.3butadiene than that of the s-trans conformer is originated from the strong steric repulsions between fluorine atoms particularly in the s-trans conformer. The resonance structures generated by NRT also show that the lone electron pairs of fluorine atoms effectively extend the conjugation. and the large differences in energy' among the structural isomers of tetrafluoro-1.3-butadiene and difluoro-1.3-butadiene are in part attributed to the differences in the delocalization energies. in addition to the steric repulsion between fluorine atoms. Other interatomic interactions. such as hydrogen bonding also play important roles in determination of the structures of isomers of tetraflıoro-1.3-butadiene and diflıoro-1.3-butadiene.
\end{abstract}

Key Words : Hexafluorobutadiene. Geometrical structure. Steric interaction. Conjugation. Natural bond orbitals

\section{Introduction}

Fluorine compounds often show unique structures and properties. For instance. the helix structures and immiscibility of perfluoro-n-alkanes and their derivatives have drawn intense attention and lead to various applications. ${ }^{1}$ Historically predicting the structures of fluorine-containing compounds has been a challenge for electronic structure methods, often requiring high levels of electron correlation and large basis sets. Recent studies. for exantple, show that accurate description of the C.F bond length of fluorinecontaining simple radicals requires calculations. at least, at the MP2/6-311(d) level. ${ }^{2}$

The structure of hexafluoro-1,3-butadiene (HFBD). the simplest perfluorocarbon with a conjugated double bond. has been the subject of many recent studies. The compound is a model systen for linear perfluoro conjugated polyenes. It has been shown experimentally as well as theoretically that the skew s-cis conformation is the most stable one rather than the s-trans conformation. Here. " $s$ " denotes the configuration along the $\mathrm{C}-\mathrm{C}$ single bond. Comparison of IR and Raman results show that the gas-phase structure of HFBD has no inversion center, indicating that the planar strans conformation is not the global energy minimum. ${ }^{3 .+}$ Brundle and Robin interpreted their photoelectron and UV spectra in terns of a nonplanar structure, and predicted a skew s-cis conformation with a twisted angle of $42^{\circ} \pm 15^{\circ}$. An electron diffraction study was also consistent with a skew $\mathrm{s}-c$ is conformation and the dihedral angle was estimated to be $47.4^{\circ} \pm 2.4^{\circ}$. A combined study of NMR. IR, and Raman spectroscopy also confinns the earlier results. ${ }^{7}$ More

\footnotetext{
Corresponding Author. Phone: +82-32-770-8235: Fax: +82-32770-8238; e-mail: bcheongàncheon ack
}

recently the vibrational spectrum of perfluoro-1.3-butadiene was assigned and the results were consistent with a $C_{2}$ structure (skew s-cis). ${ }^{8}$ The band due to the torsional motion was assigned and the barrier to planarity was estimated as $986 \pm 150 \mathrm{~cm}^{-1}$.

To date, there are only a limited number of theoretical studies of perfluorobutadiene. Choudhury and Scheiner studied the structure of perfluorobutadiene using semiempirical (MNDO and PRDDO) and $a b$ initio (STO-3G) molecular orbital methods. The MNDO potential has a skew s-trans minimum, whereas the PRDDO and STO-3G results suggest that the planar s-trans conformation is more stable. Dixon studied the structure and vibrational frequencies of HFBD with $a b$ initio methods..$^{10}$ Although calculations with the 3-21G basis set show that planar strans confonmation is more stable than the skew s-cis one, the order reverses when the same calculation is proceeded with the $6-31 \mathrm{G}^{*}$ or $\mathrm{DZ}+$ polarization basis set. The energy difference between skew $\mathrm{s}$ - $c$ is and planar s-trans conformations is $1.8 \mathrm{kcal} / \mathrm{mol}$ with the $\mathrm{DZ}+$ polarization basis set. The torsional potential shows that the minimum is at the dihedral angle of $60^{\circ}$ in skew s-cis conformation. Hudson et $a l$. perfomed $a b$ initio studies at the MP2 and B3LYP/631 (d) levels to explain their resonance Raman spectra of HFBD, and showed that the skew s-cis structure is the most stable. ${ }^{1}$ Karpfen examined the torsional potential and vibrational properties in detail at the SCF, MP2. and various DFT levels.": The study reconfirmed that the skew s-cis conformation is the global minimum.

While recent studies indicate that the skew s-cis conformation is the global energy minimum, the origin of such behavior has not been fully understood. Dixon ${ }^{10}$ and Hudson et $a .^{11}$ suggested that the steric hindrance between fluorine atoms may play an important role in deternining the 
stability of conformations of HFBD. In this study, we have carried out $a b$ initio calculations and natural bond orbital analysis for HFBD in an effort to elucidate the major factors that govern the molecular structure and energy of the fluorine-containing conjugated polyene. In addition, tetrafluoro-1,3-butadiene (TFBD) and difluoro-1,3-butadiene (DFBD) have also been studied for comparison with the results of HFBD.

\section{Computational Details}

$A b$ initio calculations are carried out with Gaussian 98 packages ${ }^{15}$ at the $\mathrm{HF}$ and MP2 levels with the $6-31 \mathrm{lG}(\mathrm{d}, \mathrm{p})$ basis set. The geometries of various structural and conformational isomers of HFBD, TFBD, and DFBD are fully optimized, subject to the molecular point group symmetry constraint, i.e. $C_{21}, C_{2}$, and $C_{2}$ for the planar s-trons, planar $s-c i s$, and skew s-cis conformations of HFBD, repectively, Fach optimized geometry was confirmed to be an energy minimum or a saddle point geometry via vibrational frequency analysis. Natural bond orbital (NBO) analysis. particularly natural steric analysis (NSA) ${ }^{1.4}$ and natural resonance theory $(\mathrm{NRT}),{ }^{15-17}$ are carried out using NWChern package. ${ }^{18}$ The exchange energy between the lone electron pairs of neighboring fluorine atoms, each of which carries three lone pairs of electrons, is estimated by NSA in order to examine the steric effects of the large radius of fluorine atom to the energy of each conformation. The C-C bond order and weights of the major resonance structures in each conformation are examined by NRT. All the NBO analyses were performed at the level of $\mathrm{HF} / 6-311 \mathrm{G}(\mathrm{d} . \mathrm{p})$ for the geometry optimized at the same level. The HF geometries show no significant differences from the MP2 geometries.

\section{Results and Discussion}

Figure 1 shows the geometries of the skew s-trans and scis conformers $\left(C_{2}\right)$ of HFBD optimized at the level of MP2/ $6-311 \mathrm{G}(\mathrm{d}, \mathrm{p})$ and numbering of atoms as well. The same numbering of atoms is also used for all other compounds in this study, L isted in Table $I$ are the geometrical parameters of several conformations of HFBD, along with those of 1,3-

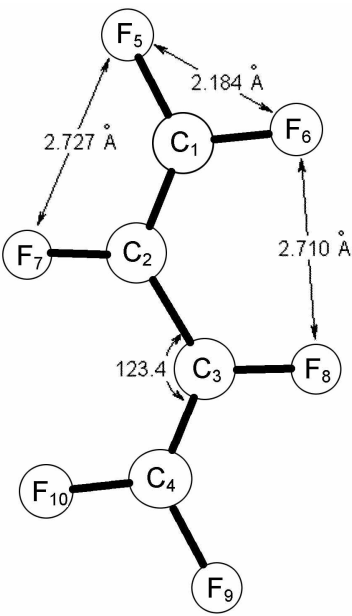

skew s-trans, 'I' $=130.5$

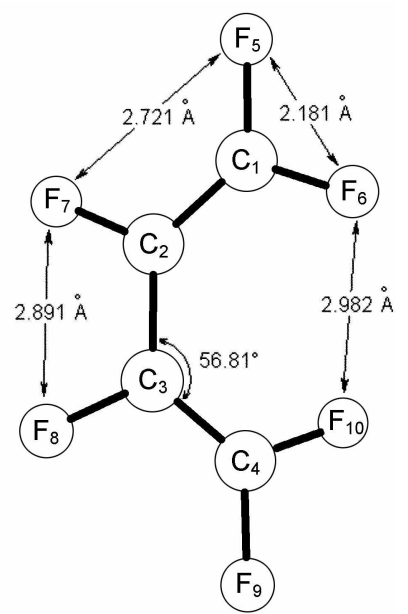

skew s-cis, ' $\mathrm{z}$ ' $=56.8$
Figure 1. The optimized geometries of the skew s-trans and s-cis conformers of HFBD. The skew s-cis conformation is the global energy minimum of HFBD. Numbering of atoms for HFBD is also shown, The same numbering scheme is used for all other llowo1.3-butadiene compounds in this stud:

Table 1. Geometrical parameters and NBO analysis of IIFBD and I.3-butadiene

\begin{tabular}{|c|c|c|c|c|c|c|c|}
\hline \multirow{2}{*}{$\frac{\text { Compound }}{\text { conformation }}$} & \multicolumn{5}{|c|}{ IIt'BD } & \multicolumn{2}{|c|}{ 1.3-butadiene } \\
\hline & planar s-trans & skent s-trans & planar s-cis & shew s-cis & expl (Rel', 6) & s-trans & $s-c i s$ \\
\hline$\overline{E^{27}}$ & -749.9248886 & -749.9261416 & -749.9188676 & -749.9277583 & & -155.5224815 & -155.5183756 \\
\hline$\Delta E^{b}$ & 0.000 & -0.786 & 3.778 & -1.801 & & 0.000 & 2.576 \\
\hline $\mathrm{r}(\mathrm{C} 2 \mathrm{C}(3)$ & 1.454 & 1.455 & 1.465 & 1.448 & 1.488 & 1.460 & 1.472 \\
\hline$r(\Gamma 5.56)$ & 2.183 & 2.184 & 2.182 & 2.181 & $2.181^{\circ}$ & 1.856 & 1.858 \\
\hline$r(\Gamma 5 . \Gamma 7)$ & 2.669 & 2.727 & 2.638 & 2.721 & $2.767^{\prime}$ & & \\
\hline$r(\Gamma 6 . \Gamma 8)$ & 2.649 & 2.710 & 4.355 & 3.910 & 4.029 & 2.499 & 3.686 \\
\hline$r(\Gamma 6 . \Gamma 10)$ & 5.145 & 4.543 & 2.593 & 2.982 & $2.858^{\circ}$ & 4.663 & 2.535 \\
\hline$r(\Gamma 7.58)$ & 3.576 & 3.447 & 2.515 & 2.891 & 2.713 & 3.122 & 2.537 \\
\hline$\Psi^{\prime \prime}$ & 180.0 & 130.5 & 0.0 & 56.8 & 47.4 & 180.0 & 39.8 \\
\hline $\mathrm{d}[(\Gamma 5: \Gamma 6) / \mathrm{d} E(\Gamma): \Gamma] 0)^{2}$ & 1.57 & 1.52 & 1.54 & 1.57 & & & \\
\hline $\mathrm{d} E(\Gamma 5: \Gamma 7) / \mathrm{dE}(\Gamma 8: \Gamma 9)^{\prime}$ & 1.00 & 0.97 & 1.16 & 0.95 & & & \\
\hline $\mathrm{dE}(\Gamma 6: \Gamma 8) / \mathrm{d} E(\Gamma 7: F] 0)^{2}$ & 1.37 & 0.70 & & & & & \\
\hline $\mathrm{d}(\Gamma(\Gamma): \Gamma 10)^{r}$ & & & 2.01 & 0.12 & & & \\
\hline $\mathrm{d} \mathrm{E}(\Gamma 7: \Gamma 8)^{\mathrm{c}}$ & & & 1.44 & 0.14 & & & \\
\hline$\Sigma \mathrm{dE}^{\prime}$ & 2.74 & 1.40 & 3.45 & 0.26 & & & \\
\hline B.O.lonic" & $1.0267 / 0.0494$ & 1.01780 .0424 & $1.0106 / 0.0345$ & $1.0115 / 0.0367$ & & $1.0331: 0.0517$ & 1.02210 .0424 \\
\hline
\end{tabular}

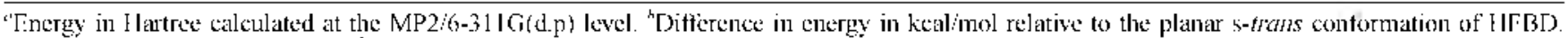
"Calculated from data in Rel. 6. "Distortion angle of the carbon skeleton in degree. "Exchange repulsion energy belween the lone electron pairs of" adjacent lluotine atoms, three pairs trom each. "Total exchange repulsion enetgy between the lone electron pairs of adjacent thorine atons excen those between geminal or syn fluorine atoms. "Iotal bond orderinonic contribution for $\left(2-C_{3}\right.$ obtained from NR']" 
butadiene for comparison. As pointed out in previous works. the planar trms structure is not an energy minimum, and among the skew structures. the s-cis conformation lies 1.015 $\mathrm{kcal} / \mathrm{mol}$ lower in energy than the s-trans one. The energy difference is consistent with the results of previous studies on the torsional potential of HFBD. ${ }^{12}$ The torsional angle $\Psi$ of the carbon skeleton in the skew s-cis structure. $56.8^{\circ}$. is slightly larger than the values estinnated in the previous electron diffraction and photoelectron studies, ${ }^{6}$ but agrees well with those of previous theoretical studies ${ }^{15 \cdot 12}$ We also optimized geometries at the HF/6-311G(d.p) level and compared the energy differences among the conformations. The results are consistent with those obtained at the MP2/6$311 \mathrm{G}(\mathrm{d}, \mathrm{p})$ level. Only noticeable difference is that the energy difference between the s-cis and s-trans conformations is smaller at the HF level.

The lower energy of the skew s-cis conformation. relative to that of the s-trans one, appears to be quite unusual on the basis of the usual assumption that the s-trons structure is more stable than the s-cis one. Evidently the skew s-cis structure of HFBD has a thread of connection with the helix structure of the perfluoro-n-alkane. ${ }^{1}$ which is more stable than the planar zig-zag structure. As Dixon found in the $a b$ initio study, ${ }^{1(1}$ the lower energy of the skew s-cis conformation is accompanied with the larger interatomic distances between adjacent fluorine atoms. Other than the distances between the geminal (F5:F6 and F9:Fl0) or syn (F5:F7 and F8:F9) fluorine atoms, the shortest interatomic distances between adjacent fluorine atoms in the skew s-cis conformation are $\mathrm{r}(\mathrm{F} 6 \mathrm{~F} 10)=2.982 \AA$ and $\mathrm{r}(\mathrm{F} 7, \mathrm{~F} 8)=2.891 \mathrm{~A}$. respectively. They are to be compared with $\mathrm{r}(\mathrm{F} 6, \mathrm{~F} 8)$ and $\mathrm{I}(\mathrm{F} 7, \mathrm{~F} 10)$, both of which are $2.649 \AA$ for the planar $\left(C_{\text {?h }}\right)$ trans structure. or $2.710 \AA$ for the skew $\left(C_{2}\right)$ s-trmas structure.

It is interesting that the interatomic distance between the syn fluorine atoms. I(F5.F7), also serves as a rough indicator for the strong steric hindrances between F6:F8 and F7:F10 in the s-trmas conformation and between F6:F10 and F7:F8 in the s-cis conformation. r(F5.F7) of planar s-trans and s-cis conformations are 2.669 and $2.638 \AA$. respectively. whereas those of skew s-trons and s-cis conformations are 2.727 and $2.721 \AA$ A. respectively. Note that the van der Waal radius of fluorine atom is about $1.47 \mathrm{~A}$. The steric hindrance is expected most severe in the planar s-cis conformation: the steric hindrances between F6:FI0 and between F7:F8 cause the syn fluorine atoms (F5:F7) to be closer, resulting in a short distance of $2.638 \AA$. However. the steric hindrances are much less significant in the skew s-cis structure. leading to a larger distance of 2.721 A. Another evidence of the severe steric hindrance in the planar s-cis structure is the longer C$\mathrm{C}$ bond, which is stretched out to alleviate the strong steric hindrances between the adjacent fluorine atoms.

However, those interatomic distances are all indirect evidences for the steric hindrances. When two fluorine atonis approach each other, the large electron clouds of lone electron pairs of the two fluorine atoms start interacting. causing steric repulsion. Recently Badenhoop and Weinhold have introduced an effective way of estimating the degree of the steric hindrance, called natural bond analysis of steric interactions. ${ }^{14}$ The NBO decomposition of the wave function into localized bond and lone pair orbitals allows the steric repulsion to be expressed in terms of relative energy changes of individual NBOs upon orthogonalization, consistent with earlier treatment of "Pauli repulsions." 19 The approach separates the purely steric or exchange contributions from delocalization or charge transfer, induction, electrostatic. or other effects. Quantitative estimation of steric repulsion between fluorine atoms in HFBD would provide more direct verification for the lower energy of the s-cis conformation. Therefore. NSA has been conducted in order to examine closely the exchange repulsions between the lone electron pairs of contacting fluorine atoms.

The exchange repulsion energies $\mathrm{dE}$ between the adjacent fluorine atoms of HFBD obtained by NSA are listed in Table 1. The present analysis show that the exchange repulsions between syn or geminal fluorine atoms change only slightly regardless of the molecular conformation. However. the exchange repulsions between other adjacent fluorine atoms vary dramatically with the conformations. Table 1 shows that the large exchange repulsion energies. $\mathrm{dE}(\mathrm{F} 6 \mathrm{~F} 8)$ and $\mathrm{dE}(\mathrm{F} 7: \mathrm{Fl0})$ for the s-trans conformation and $\mathrm{dE}(\mathrm{F} 6: \mathrm{Fl} 10)$ and $\mathrm{dE}(\mathrm{F} 7: \mathrm{F} 8)$ for the $\mathrm{s}$-cis conformation, in the planar structures are greatly reduced in the skew structures. consistent with the variation of interatomic distances between the fluorine atoms. The total exchange repulsion $\Sigma \mathrm{dE}$ between fluorine atoms is, as shown in Table 1 . the lowest in the skew s-cis conformation. Distortion of the s-cis conformer greatly increases the interatomic distances, $r(F 6, F 10)$ and $r(F 7 . F 8)$. which in turn reduce the steric repulsions between the fluorine atoms. On the other hand, distortion of the s-trons conformer does not changes $\mathrm{r}(\mathrm{F} 6 . \mathrm{F} 8$ ) and $\mathrm{r}(\mathrm{F} 7, \mathrm{~F} 10)$ as much. The present results on the variation of interatomic distances between the fluorine atoms and the exchange repulsion energies indicate that the stability of the skew conformations of HFBD are largely attributed to the steric hindrance between adjacent fluorine atoms. due to the large van der Waals radius. And among the two skew conformations, the skew s-cis conformer is more stable because of the lower steric hindrance between fluorine atoms in the structure. relative to that of the skew s-trans conformer.

As another factor that may affect the structures of the conformations, we consider the change in conjugation along the carbon skeleton. As shown in Table 1, the difference in total exchange repulsion energy is slightly larger than the difference in energy between the conformations. The conjugation energy will be certainly reduced in the skew structures. particularly in the skew s-cis confommation with the large torsional angle of almost $60^{\circ}$. It is thus expected that the difference in energy between the conformations is roughly equal to the differences in the total exchange repulsion and the conjugation energy. In order to estimate the magnitude of the conjugation energy, NRT ${ }^{15-17}$ analysis is proceeded. which estimates the bond order and valency 
HFBD

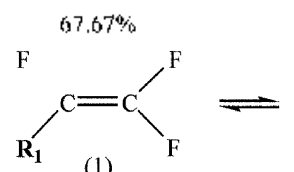

(1)
(2)<smiles>[R]C(F)(F)C(F)=[Fe]</smiles>

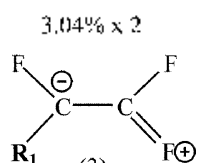

(3)<smiles>[R]C(=[Fe])C(F)=[W]</smiles>

(4)<smiles>[R4]C(F)=C=[Fe+]</smiles>

(5)<smiles>C=CCCCCC(F)(F)C(=O)F</smiles>

(7)<smiles>[R1][X]F</smiles><smiles></smiles>

\section{1,3-Butadiene}<smiles>[R]C=CC=C</smiles>

(1)<smiles>C=CC=O</smiles>

(2)

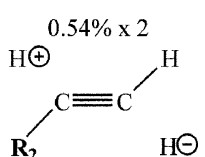

(3)
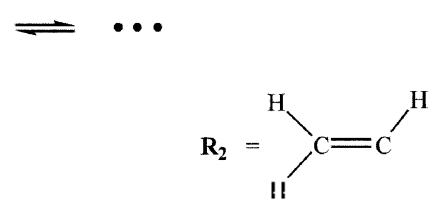<smiles></smiles>

Figure 2. The major resonance structures of the skew s-cis conformer of HFBD and 1.3-butadine. The weights of the resonance structures are also shown. Fssentially the same resonance siructures with similar weights are found for the s-trans conformer.

that are closely related to classical resonance theory concepts. The estimated bond orders of the $\mathrm{C}-\mathrm{C}$ bond in HFBD conformers, along with the ionic contributions, are listed in Table 1. The planar s-trans conformation, which is more favorable in terms of conjugation energy, carries a slightly higher bond order with a higher ionic contribution. The higher ionic contribution to the total bond order is certainly correlated with the resonance structures having electric charges along the $\mathrm{C}-\mathrm{C}$ bond. Despite the changes in the bond order, the $\mathrm{C}-\mathrm{C}$ bond is essentially a single bond, as shown in Jable 1, and the bond order varies only slightly about 0.015 depending on the conformations.

The major resonance structures of skew s-cis HrBD, generated from NRI analysis, are compared with those of 1,3-butadiene in Figure 2. where the structures are shown in the decreasing order of resonance weights. The weights of the resonance structures of the s-cis conformer are almost the same as those of the s-cis conformer. The resonance structures clearly show that the lone electron pairs of

fluorine atoms effectively extend the conjugation, and most variations in the resonance structures occur around the $\mathrm{C}=\mathrm{C}$ bonds. It is also notable that the weight of resonance structure (7), which gives the double bond character to the $\mathrm{C}-\mathrm{C}$ bond, is in fact relatively small and similar to that of resonance structure (2) of 1,3-butadiene. Therefore, it is expected that rotation along the $\mathrm{C}-\mathrm{C}$ bond of $\mathrm{HF} \mathrm{BD}$ increases the molecular energy only slightly, which can be easily compensated by reduction in the exchange repulsion between fluorine atoms. Simple multiplication of the bond energy (normally about $88 \mathrm{kcal} / \mathrm{mol}$ ) of a single $\mathrm{C}-\mathrm{C}$ bond and the increase in bond order $(0.0267)$ of the $\mathrm{C}-\mathrm{C}$ bond of planar s-trans HFBD gives less than $2.4 \mathrm{kcal} / \mathrm{mol}$. By rotation along the $\mathrm{C}-\mathrm{C}$ bond, this conjugation energy reduces to 1.6 and $1.0 \mathrm{kcal} / \mathrm{mol}$ for the s-trans and s-cis conformations, respectively.

Next we have conducted $a b$ initio and NBO calculations for several structural as well as conformational isomers of tetrafluoro-1,3-butadiene and difluoro-1,3-butadiene. The steric hindrance between fluorine atoms is expected much lower in these partly fluorinated conjugated polyenes. However, there may be other important interatomic interactions affecting the geometry of the conformers, such as hydrogen bonding with fluorine atoms or $\pi$-electrons. It has been reported that the s-cis conformer is the most stable one for some of partly chlorinated or brominated 1,3-butadiene compounds. ${ }^{7}$ Both chlorine and bromine atoms carry much larger van der Waals radii than the fluorine atom does. causing stronger steric hindrance, but they are expected to form much weaker hydrogen bonds. Therefore, partly fluorinated 1,3-butadiene compounds are again good model compounds to examine the importance of the steric hindrance between fluorine atoms, along with effects of other interatomic interactions in partly halogenated polyenes.

Figure 3 shows the structures of five TFBD compounds, and Table II lists their geometrical paraneters optimized at the MP2/6-311G(d,p) level, 1,1,4,4-TFBD is the lowest in molecular energy among the TFBD compounds studied, and $1,2,3,4-T F B D$ (I) the highest. The difference in energy more than $20 \mathrm{kcal} / \mathrm{mol}$ is not usual for compounds with the same chemical formula and no particular strain or variation in the structure. The major resonance structures for the skew s-cis conformers of 1,1,4,4-] THBD and 1,2,3,4-[1-BD (I) generated by NR' analysis are shown in rigure 4 . The s-trans conformers also have essentially the same resonance structures with similar weights. Clearly, the weights of the resonance structures other than structure (1) are greater for $1,1,4,4-1$ ' $B D$, and structures (4) and (5) are not even found from 1,2,3,4-TFBD (I) in Figure 4. The lone electron pairs of fluorine atoms extend the conjugation. and the positive charge on a fluorine atom in resonance structures (2)-(5) of $1,1,4,4-T-B D$ is stabilized by the neighboring electron-rich fluorine atom. On the other hand, the negative charge of resonance structures (2) and (3) of 1,2,3,4-[r-BD is located next to another fluorine atom, causing coulombic repulsion with the electron-rich fluorine atom. The present NRI result clearly indicates that the low energy of $1,1,4,4-1 \mathrm{HBD}$ is 


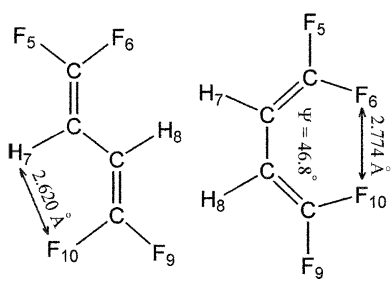

I, I, 4, 4-TFBD

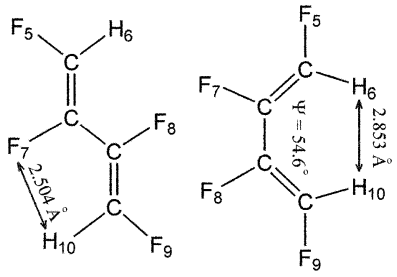

$1,2,3,4-\mathrm{TFBD}(\mathrm{II})$

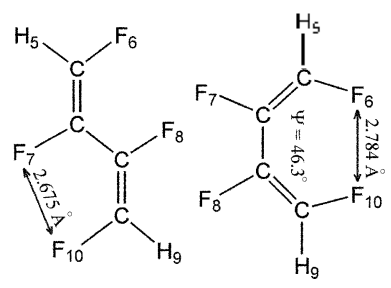

1,2.3.4-TFBD (1)<smiles>Cc1c(F)c(F)c(F)c(F)c1F</smiles>
1,2,3,4-TГ'BD (III)<smiles>Cc1c(F)c(F)c(F)c(F)c1F</smiles>

1,1,2,3-TFBD
Figure 3. Conformations of the TFBD compounds studied in this work. The interatomic distances between atoms 6 and 10 and distortion angles of the skew s-cis conformers are indicated. All the s-frams conformers have planar structures. and the interatomis distances between atoms 6 and 8 and between atoms 7 and 10 are also indicated.

mainly attributed to the delocalization stabilization.

Unlike HFBD, the planar s-trans conformation is the energy minimum rather than the skew s-trans structure for all TFBD compounds studied. Among the THBD's studied here, only 1,1,4,4-1 THBD has been the subject of experimental structural studies. Mutual exclusion of infrared and Raman frequencies are observed in a previous study ${ }^{20}$ of $1,1,4,4-\left[\mathrm{HBD}\right.$, and $\mathrm{NMR}^{21}$ and $\mathrm{X}$-ray ${ }^{22}$ results are also consistent with a planar s-trans conformation. The hydrogen atoms in the IHBD's greatly reduce the chances of steric repulsion between fluorine atoms particularly in the s-irans conformation. Only 1,2,3,4-[HBD (I) has both $16: 58$ and $F 7: F 10$ contacting fluorine atom pairs. However, even in this compound, the steric repulsion is expected to be much weaker than in HFBD since the fluorine atoms have more room to sway due to lack of steric repulsions between the geminal and the syn fluorine atoms. As a result, the planar srans conformation becomes the energy minimum for all five I'HBD's, and they are also the global minimum except for $1,2,3,4-\mathrm{I}+\mathrm{BD})(\mathrm{I})$.

For 1,2,3,4-THBD (1), the skew s-cis conformer is the global energy minimum. 1.2.3,4-[r $\mathrm{CDD}(\mathrm{l})$ is also the highest in molecular energy among the three isomers of 1,2,3,4-
$1,1,4,4-T \mathrm{HBD}$<smiles>[R3]C=C(F)F</smiles><smiles></smiles><smiles>C=C([13CH2])F</smiles>

\section{$1,2,3,4-\mathrm{Tl} \cdot \mathrm{BD}(\mathrm{J})$}

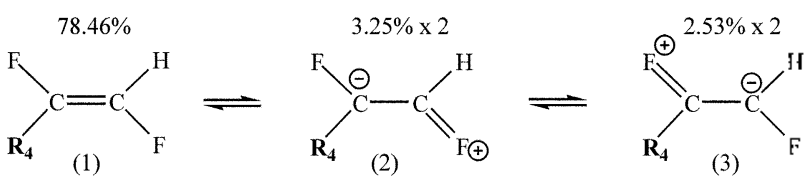<smiles>C=CCCCC(=O)F</smiles><smiles>[R]C=C([1H])F</smiles><smiles>O=[CH+]CF</smiles>

Figure 4. The major resonance structures of the skew s-cis conformers of I.I.4.4-TFBD and 1.2.3.4-TFBD (I). The weights of the resonance structures are also shown. Fssentially the same resonance structures wibl similar weights are lound for the s-trans conformers.

[FBD's studied. For the s-rmans conformer of 1,2,3,4-]FBD (I), strong steric repulsions are expected between the fluorine atoms ( $166: \mathrm{F} 8$ and $177: 510)$ on the basis of the small interatomic distances, while for the s-cis conformer, the steric repulsions between $\mathrm{F} 6: \mathrm{F} 10$ and $\mathrm{F} 7: \mathrm{F} 8$ are reduced greatly by distortion of the carbon skeleton. The NSA results summarized in Table 2 also show that the steric repulsions between fluorine atoms are indeed much lower in the skew s-cis conformer than in the planar s-trans conformer only in $1,2,3,4-1$ - $B$ BD (I). Therefore, the lower energy of the skew scis conformer of 1,2,3,4-THBD (I), relative to that of the skew s-Irans one, is primarily attributed to the lower steric repulsions between fluorine atoms, similar to that found in $\mathrm{HFBD}$.

$1,2,3,4-1 F B D$ (I]) is the lowest in energy among the isomers of $1,2,3,4-\mathrm{THBD}$. For the s-cis conformer of $1,2,3,4-$ IFBD (II), the hydrogen atoms at atomic positions $\mathrm{H} 6$ and $\mathrm{H} 10$ eliminate the steric repulsion between $\mathrm{F} 6$ and $\mathrm{F} 10$ that exists in the s-cis conformer of $1,2,3,4-[1 \mathrm{BD}$ (I) (see figure 3). Elimination of steric repulsion between fluorine atoms also occurs greatly in the s-irans conformer, leading to a 
Table 2. Geometrical parameters and NBO analy sis of TFBD's

\begin{tabular}{|c|c|c|c|c|c|c|c|c|c|c|}
\hline \multirow{2}{*}{$\begin{array}{l}\text { compound } \\
\text { conformation }\end{array}$} & \multicolumn{2}{|c|}{$1,1,4,4-$ TFBD } & \multicolumn{2}{|c|}{$1,2,3,4-\mathrm{TFBD}$ (I) } & \multicolumn{2}{|c|}{$1,2,3,4-\mathrm{TFBD}$ (II) } & \multicolumn{2}{|c|}{$1,2,3,4$-TFBD (III) } & \multicolumn{2}{|c|}{$1,1,2,3-\mathrm{TFBD}$} \\
\hline & s-trans & skew s-cis & s-trans & skew s-cis & s-trans & skew s-cis & s-trans & skew s-cis & s-trans & skew s-cis \\
\hline$\overline{E^{\sigma}}$ & -551.820771 & -551.8160088 & -551.7825349 & -531.7835201 & -531.788367 & -551.7858815 & -551.785586 & $1-551.7842974$ & -51.7976057 & -551.7947397 \\
\hline$\Delta \mathrm{E}^{b}$ & 0.000 & 2.675 & 23.994 & 23.375 & 20.333 & 22.082 & 22.079 & 22.888 & 14.537 & 16.335 \\
\hline $\mathrm{I}(\mathrm{C} 2, \mathrm{C} 3 \mathrm{3})$ & 1.453 & 1.464 & 1.456 & 1.457 & 1.455 & 1.456 & 1.455 & 1.458 & 1.458 & 1.461 \\
\hline$I(5,6)$ & 2.171 & 2.165 & 2.044 & 2.784 & 2.049 & $2.0+4$ & 2.047 & 2.046 & 2.179 & 2.181 \\
\hline$r(5,7)$ & 2.574 & 2.548 & 2.528 & 2.588 & 2.729 & 2.741 & 2.540 & 2.581 & 2.670 & 2.706 \\
\hline$\tau(6,8)$ & 2.620 & 3.836 & 2.675 & 4.021 & 2.504 & 3.756 & 2.721 & 4.032 & 2.663 & 4.052 \\
\hline$\tau(6,10)$ & 5.039 & 2.774 & 5.171 & 2.784 & 4.704 & 2.853 & 4.929 & 2.724 & 4.901 & 2.705 \\
\hline$\pi(7,8)$ & 3.164 & 2.632 & 3.561 & 2.755 & 3.553 & 2.865 & 3.558 & 2.763 & 3.553 & 2.707 \\
\hline$I(7,10)$ & 2.620 & 3.836 & 2.675 & 4.021 & 2.504 & 3.756 & 2.419 & 3.860 & 2.479 & 3.915 \\
\hline$I(8,9)$ & 2.574 & 2.548 & 2.528 & 2.588 & 2.729 & 2.741 & 2.722 & 2.741 & 2.580 & 2.582 \\
\hline$r(9,10)$ & 2.171 & 2.165 & 2.044 & 2.047 & 2.049 & 2.041 & 2.047 & 2.046 & 1.876 & 1.872 \\
\hline$\Psi^{\prime}$ & 180.0 & 46.8 & 180.0 & 46.3 & 180.0 & 54.6 & 1800 & 45.9 & 180.0 & 42.5 \\
\hline $\mathrm{dE}(\mathrm{F} 5, \mathrm{~F} 6)^{7}$ & 1.68 & 1.76 & & & & & & & 1.66 & 1.49 \\
\hline $\mathrm{dE}\left(\mathrm{F} 5, \mathrm{~F} 7 \gamma^{7}\right.$ & & & & & 0.77 & 0.82 & & & 1.01 & 0.97 \\
\hline $\mathrm{dE}(\mathrm{F} \sigma, \mathrm{F} 8)^{7}$ & & & 1.19 & & & & 0.98 & & 1.40 & \\
\hline $\mathrm{dE}(\mathrm{F} 6, \mathrm{~F} 10)^{7}$ & & 0.35 & & 0.37 & & & & & & \\
\hline $\mathrm{dE}(\mathrm{F} 7, \mathrm{~F} 8)^{7}$ & & & & 0.32 & & 0.17 & & 0.36 & & 0.44 \\
\hline $\mathrm{dE}(\mathrm{F} 7, \mathrm{~F} 10)^{7}$ & & & 1.19 & & & & & & & \\
\hline $\mathrm{dE}(\mathrm{F} 8, \mathrm{~F} 9)^{7}$ & & & & & 0.77 & 0.82 & 0.84 & 0.81 & & \\
\hline $\mathrm{dE}(\mathrm{F} 9, \mathrm{~F} 10)^{7}$ & 1.68 & 1.76 & & & & & & & & \\
\hline$\Sigma \mathrm{dE}^{e}$ & 0.00 & 0.35 & 2.38 & 0.69 & 0.00 & 0.17 & 0.98 & 0.36 & 1.40 & 0.44 \\
\hline B. 0 /lonic & $1.0264 /$ & $1.0174 /$ & $1.0226 /$ & $1.0114 /$ & $1.0238 /$ & $1.0176 /$ & $1.0217 /$ & $1.0137 /$ & $1.0170 /$ & $1.0107 /$ \\
\hline & $0.04+2$ & 0.0361 & 0.0477 & 0.0384 & 0.0474 & 0.0441 & 0.0498 & 0.0435 & 0.0658 & 0.0587 \\
\hline
\end{tabular}

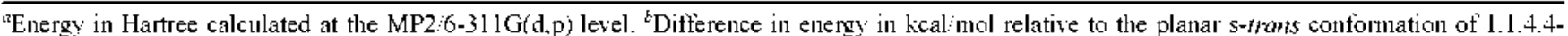
TFBD. 'Distortion angle of the carbon skeleton in degree. 'Exchange repulsion energy between the lone electron pairs of adjacent fluorine atoms. three pairs from each. "Total exchange repulsion energy between the lone electron pairs of adjacent fluorine atoms except those between geminal or syn fluonine atoms. Total bond order ionic contribution for C2-C3 obtained from NRT.

lower energy of $1.75 \mathrm{kcal} / \mathrm{mol}$ relative to that of the skew scis conformer. However it is interesting that despite the less degree of repulsion. the interatomic distance between $\mathrm{H} 6$ and $\mathrm{H} 10$ in the skew s-cis conformer of 1.2.3.4-TFBD (II) is larger than that between F6 and F10 in the skew s-cis conformer of 1.2.3.4-TFBD (I) as shown in Figure 3. The larger interatomic distance stems from the larger distortion of the carbon skeleton in 1.2.3.4-TFBD (II). which, in turn. leads to a larger distance between F7 and F8.

Table 2 shows that the exchange repulsion between $\mathrm{F} 7$ and F8 of 1.2.3.4-TFBD (II) is the smallest among the 1.2.3.4TFBD's. This suggests that the hy'drogen atoms may interact strongly' with the $\pi$-electrons and/or the fluorine atoms on the opposite side of the molecule. Large distortion of the carbon skeleton causes the hydrogen atom to locate closer to and above the double bond. possibly forming a hydrogen bond with $\pi$-electrons. similar to those hydrogen bonds observed in many crystal structures. where $\pi$-electrons in multiple bonds and aromatic rings function as weak hydrogen bond acceptors. ${ }^{23}$ The distortion also shortens the distance to the fluorine atoms on the opposite side. increasing the possibility of interaction through hydrogen bonds or dipole interactions. However. the interaction between the hydrogen and fluorine atoms is probably not so strong due to the large interatomic distances $(\sim A)$ in 1.2.3.4-TFBD (II). A strong evidence of hydrogen bonding with a fluorine atom is found in the skew s-cis conformer of 1.2.3.4-TFBD (III). In the skew s-cis conformer. the hydrogen ( $\mathrm{H} 10)$ and the fluorine atoms (F6) at the ends are located closer to each other in comparison with the corresponding atoms of other 1.2.3.4-TFBD's. while the steric repulsions between $\mathrm{F} 7$ and $\mathrm{F} 8$ are expected similar in all three compounds. Another evidence of hydrogen bonding with fluorine is found from 1.1.2.3-TFBD. The interatomic distance between $\mathrm{H} 6$ and $\mathrm{F} 10$ is the shortest among the corresponding distances of the five TFBD's. and the distortion angle is smallest. We. therefore. conclude that not only the steric repulsion between fluorine atoms but other interactions such as hydrogen bonding may play significant roles in determination of the structure of a conjugated fluorocarbon.

Figure 5 shows the structures of the five DFBD compounds studied, and the optimized geometrical parameters are summarized in Table 3. 1.2-DFBD is the highest in energy among the DFBD's and 1.4-DFBD the lowest. The molecular energy varies more than $8 \mathrm{kcal} / \mathrm{mol}$ among the DFBD's. Figure 6 shows the major resonance structures of the skew scis conformers of 1.2-DFBD and 1.1-DFBD. Clearly 1.1DFBD has more effective resonance structures, and particularly resonance structures (5) and (6) are not even present for 1.2-DFBD. The lone electron pairs of fluorine atoms again extend the conjugation, and the resulting positive 
<smiles>CC(F)=C1[CH+]PCC(C)=C1C</smiles>

1,2-DFBD<smiles></smiles>

1,4-DFBD (11)

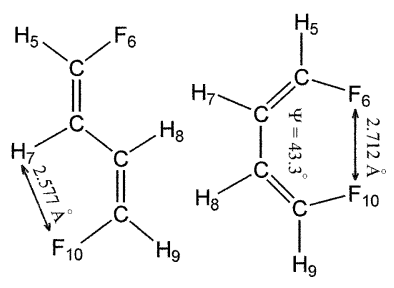

1,4-DFBD (I)<smiles>CC(C)=C(F)C(F)=C(C)C</smiles>

2,3-DFBD

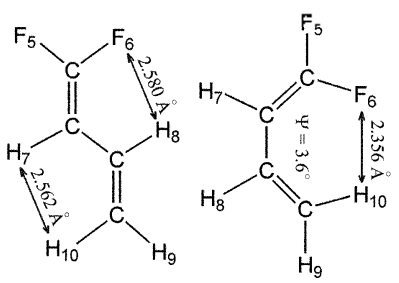

1.1-DFBD

Figure 5. Conformations of the DFBD compounds studicd in this work. The interatomic distances between atoms 6 and 10 and distortion angles in the skew s-cis conformers are indicated. All the s-trans conformers have planar structures and are the global energy minima. The interatomic distances between atoms 6 and 8 and belween atoms 7 and 10 in the s-frans conformers are also indicaled.

charge on a fluorine atom is stabilized by the neighboring electron-rich fluorine atom in 1,1-DГВD. On the other hand. the negative charge in a resonance structure of 1,2-DFBD is often located next to the other fluorine atom. causing Coulombic repulsion with the electron-rich fluorine atom. The order in molecular energies of DFBD's in lable 3 can be explained in terms of the stability of the major resonance structures.

For all five compounds of DFBD, the planar s-rrans conformation is the global energy minimum, which is consistent with previous experimental results. ${ }^{7.24 .25}$ The geometrical parameters of the conformers of 1.4-DFBD are in good agreement with the results of a recent $a b$ inirio study for 1,4-DFBD isomers. ${ }^{26}$ Similar to the case of THBD, an evidence of intramolecular interaction other than steric repulsion of fluorine atoms is found from 1.4-DFBD. Despite the absence of steric repulsion between fluorine atoms, the interatomic distance of $2.737 \AA$ between $\mathrm{H} 6$ and $\mathrm{H} 10$ of scis 1,4-Dr-BD (II) is larger than that of $2.712 \AA$ between 16 and $F 10$ in s-cis 1,4-DPBD (l), and the distortion angle is also larger in 1.4-DFBD (II). This large distortion moves the hydrogen atoms to a location favorable to form a hydrogen bond with $\pi$-electrons. Another strong evidence of intra-

\section{1,2-DFBD}

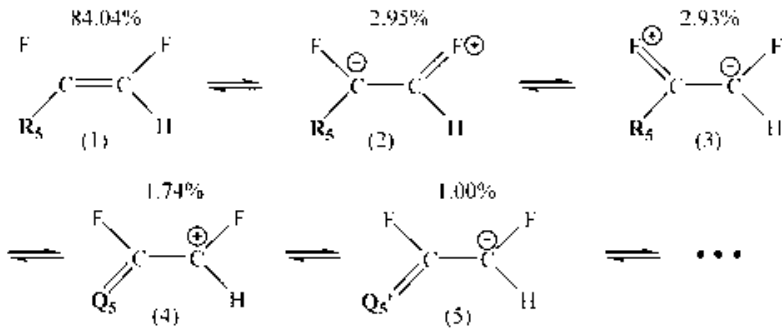<smiles>[3H]C=[V][3H]</smiles>

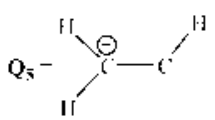

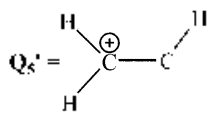

\section{1,1-DFBD}<smiles>[R]C=C(F)C(F)=CC</smiles><smiles>[R]C(=O)C(=O)F</smiles><smiles>[2H]C(=O)F</smiles><smiles>C=CC(=O)C(F)(F)C=C</smiles><smiles>[R]/C=C\C=C=O</smiles><smiles>C=CC(=O)C(F)(I)C=CC</smiles><smiles>[3H]C=C[12CH2]</smiles><smiles>[1H]C[13CH2][18OH]</smiles><smiles>[13CH2]C[18OH]</smiles>

Figure 6. The major resonance structures of the skew s-cis conformers of 1.2-DFBD and 1.1-DFBD. The weights of the resonance structures are also shown. Fssentially the same resonance structures will similar weights are found for the s-trans conformers.

molecular hydrogen bonding is found from the skew s-cis conformation of $1,1-D F B D$, where $r(6,10)$ is surprisingly small $(2.356 \AA$ ) and the conformer is nearly planar ( $\Psi=$ $3.6^{\circ}$ ). The strong hydrogen bond between the hydrogen and fluorine atoms ties them together and suppresses the carbon skeleton from distortion.

\section{Conclusions}

Ab initio studies along with natural resonance theory and natural steric analyses have been carried out for fluoro- 1,3butadiene compounds, $\mathrm{HFBD}$, THBD, and DFBD. Strong steric repulsions are present between fluorine atoms in conjugated fluoropolyenes, often causing unusual structures. Particularly the large steric repulsions in the planar structures of HFBD lead to the stable skew s-mans and s-cis conformations. The NSA results indicate that the low energy of the skew s-cis conformation of $\mathrm{HrBD}$ is attributed to the relatively weaker steric repulsions between the fluorine 
Table 3. Geometrical parameters and NBO analy sis of DFBD's

\begin{tabular}{|c|c|c|c|c|c|c|c|c|c|c|}
\hline \multirow{2}{*}{$\begin{array}{l}\text { compound } \\
\text { confonnation }\end{array}$} & \multicolumn{2}{|c|}{ 1,2-DFBD } & \multicolumn{2}{|c|}{1,4 -DFBD (I) } & \multicolumn{2}{|c|}{ 1,4-DFBD (II) } & \multicolumn{2}{|c|}{ 2,3-DFBD } & \multicolumn{2}{|c|}{$1,1-\mathrm{DFBD}$} \\
\hline & s-trans & skew s-cis & s-trans & skew s-cis & s-trans & skew s-cis & s-trans & skew s-cis & s-trans & skew s-cis \\
\hline $\mathrm{E}^{\sigma}$ & -353.6586949 & -353.6543067 & $-353,666228$ & -35365999525 & -353.662630 & -353.6598682 & -333668421 & -353.6627250 & -353672217 & $-353,6679749$ \\
\hline$\Delta \mathrm{E}^{b}$ & 0000 & 2.754 & -4.728 & -0.789 & -2.470 & -0.736 & -6.104 & -2.529 & -8.485 & -5.823 \\
\hline$I(\mathrm{C} 2, \mathrm{C} 3)$ & 1.453 & 1.461 & 1.454 & 1.465 & 1.454 & 1.467 & 1.466 & 1.471 & 1.456 & 1.464 \\
\hline$T(5,6)$ & 2.045 & 2.047 & 2.028 & 2.022 & 2.029 & 2.031 & 1.876 & 1.873 & 2.167 & 2.164 \\
\hline$T(5,7)$ & 2.723 & 2.726 & 2.459 & 2.417 & 2.566 & 2.573 & 2.584 & 2.585 & 2.572 & 2.525 \\
\hline $\mathrm{r}(6,8)$ & 2.499 & 3.683 & 2.577 & 3.866 & 2.575 & 3.638 & 2.469 & 3.882 & 2.580 & 4.043 \\
\hline$I(6,10)$ & 4.672 & 2.615 & 5.020 & 2.712 & 4.732 & 2.737 & 4.648 & 2.629 & 4.861 & 2.356 \\
\hline$T(7,8)$ & 3.340 & 2.632 & 3.146 & 2.576 & 3.157 & 2.661 & 3.533 & 2.668 & 3.142 & 2.4 .32 \\
\hline$I(7,10)$ & 2.498 & 3.893 & 2.577 & 3.866 & 2.575 & 3.638 & 2.469 & 3.882 & 2.562 & 3.904 \\
\hline$T(8,9)$ & 2.451 & 2.454 & 2.459 & 2.417 & 2.566 & 2.573 & 2.584 & 2.585 & 2.440 & 2.390 \\
\hline$r(9,10)$ & 1.860 & 1.858 & 2.028 & 2.022 & 2.029 & 2.031 & 1.876 & 1.873 & 1.857 & 1.854 \\
\hline$\Psi^{\prime}$ & 180.0 & 42.2 & 180.0 & 43.3 & 180.0 & 49.1 & 180.0 & 40.9 & 180.0 & 3.6 \\
\hline $\mathrm{dE}(\mathrm{F} ;, \mathrm{F} 6)^{7}$ & & & & & & & & & 1.75 & 1.90 \\
\hline $\mathrm{dE}(\mathrm{F} ;, \mathrm{F})^{7}$ & 0.78 & 0.81 & & & & & & & & \\
\hline $\mathrm{dE}(\mathrm{F} \sigma, \mathrm{F} 10)^{7}$ & & & & 0.51 & & & & & & \\
\hline $\mathrm{dE}(\mathrm{F} 7, \mathrm{~F} 8)^{7}$ & & & & & & & & 0.62 & & \\
\hline$\Sigma \mathrm{dE}^{e}$ & 0.00 & 0.00 & 0.00 & 0.51 & 0.00 & 0.00 & 000 & 0.62 & 0,00 & 0.00 \\
\hline B.O/Lonic & $\begin{array}{l}1.0315 / \\
0.0563\end{array}$ & $\begin{array}{l}1.0200 / \\
0.0443\end{array}$ & $\begin{array}{l}1.0257 / \\
0.0433\end{array}$ & $\begin{array}{l}1.0240 / \\
0.0430\end{array}$ & $\begin{array}{l}1.0384 / \\
0.0551\end{array}$ & $\begin{array}{l}1.0236 / \\
0.0420\end{array}$ & $\begin{array}{l}10173 / \\
0.0470\end{array}$ & $\begin{array}{l}1.0044 / \\
0.0355\end{array}$ & $\begin{array}{l}1.0290 / \\
0.0726\end{array}$ & $\begin{array}{l}1.0209 / \\
0.0654\end{array}$ \\
\hline
\end{tabular}

"Energy in Hartree calculated at the MP2:6-311G(d.p) level. "Difference in energy in kcalimal relative to the planar s-frons conformation of 1.2 -DFBD. 'Distortion angle of the carbon skeleton in degree. "Exchange repulsion energy between the lone electron pairs of adjacent fluorine atoms. three pairs from each. "Total exchange repulsion energy between the lone electron pairs of adjacent fluorine atoms except those between geminal or syn flurine atoms. Total bond order ionic contribution for C2-C3 obtained from NRT.

atomis in the molecular structure. According to the results of NRT analysis, the C-C bond of 1,3-butadiene is essentially a single bond, and remains almost the same even after substitution with fluorine atoms. Substitution of fluorine atonts effectively extends the conjugation. and in the resonance structures, the electron-rich fluorine atom can stabilize a positive charge nearby. The unusually large differences in molecular energy among the compounds of TFBD and DFBD are attributed to the differences in delocalization energies. While the steric repulsion between fluorine atonts is an important factor in deternination of the molecular structure of the conjugated fluoropolyene. evidences also suggest that other interatomic interactions, such as hydrogen bonding. play important roles.

\section{References}

1. Cho. H.-G.: Strauss. H. L.: Snyder. R. G. J. Phs. Chem. 1992. 96. 5290 .

2. Cheong B.-S.: Cho. H.-G. J. Phys Chent A 1997, 101. 7901

3. Albright. J. C.: Nielsen. J. R. J Chem. Phvs. 1957. 26. 370 .

4. Beaudet. R. A.J.Am. Chem. Soc. 1965.87. 1390.

5. Brundle. C. R.: Robin. M. B. J. Am. (chem. Soc. 1970. 92. 5550.

6. Chang. C. H.: Andreassen. A. L.: Bauer. S. H. J. Org. Chem. 1971. 36,920 .

7. Toth. I. P: Koster. D. F. Spectrochin. Acta 1975.31.4. 1891.

8. Wurrey C. J: Bucy. W. E.: Durig. I. R. J. Chem. Phws. 1977.67. 2765 .

9. Choudhury. T.: Scheiner. S. J. Hol. Struct. (Theochem. 1984. 109. 373.

10. Dixon. D. A. J. Plvs Chem 1986,90,2038.

11. Foles, M. S. C.: Braden. D. A.: Hudson. B. S.: Zgierski. M. Z. J. Phys Chent A 1997, 101. 1455.
12. Karpien. A. J. Phys. Chem. A 1999. 103. 2821

13. Frisch. M. J:: Truchs. G. W: Schlegel. H. B.: Scuseria. G. E.: Robb. M. A.; Cheeseman. J. R.: Zakrzewski. V. G.: Montgomery. J. A.. Jr.: Stratmann, R. E.; Burant, J. C.: Dapprich. S.; Millam. J. M: Daniels. A. D.: Kudin. K. N.: Strain. M. C.: Farkas. O.; Tomasi. T.: Barone. V: Cossi. M.: Cammi. R.: Mennucci. B.: Pomelli. C.: Adamo. C.: Clifford. S.: Ochterski. T.: Petersson. G. A.: Ayala. P. Y.: Cui. Q.: Morokumna. K.: Malick. D. K.: Rabuck. A. D.: Raghavachari. K: Foresman, J. B.; Cioslowshi. J.; Ortiz. J. V.: Stefanov, B. B.: Liu, G.; Liashenko, A.; Piskorz, P.: Komaromi. I.; Gomperts. R: Martin. R. L.: Fox, D. J.; Keith, T: Al-Laham. M. A.: Peng. C. Y.: Nanayakkara. A.: Gonzalez. C.: Challacombe. M.: Gill. P. M. W.: Johnson1. B.: Chen. W.: Wong. M. W.: Andres. J. L.: Gonzalez. C.: Head-Gordon. M.: Replogle. E. S.: Pople. J. A. Gaussian 98. Revision A.7; Gaussian, Inc.: Pittsburgh. PA. 1998.

14. Badenhoop. J. K.: Weinhold, F. J. Chem. Phy 1997, 107, 5406.

15. Glendening. E. D.; Weinhold. F. J. Comput Chent 1998, 19, 593.

16. Glendening. E. D.: Weinhold. F. J. Comput Chem 1998. 19.610.

17. Glendening. E. D.: Badenhoop. J. K.: Weinhold. F. J. Comput. Chem. 1998. 19.628.

18. High Performance Computational Chemistry Group. NWChem. A Contputational Chemistr Pachage for Parallel Computers Tersion 4.1: Pacific Northwest National Laboratory: Richland. WA. 20012.

19. Sovers. O. J.: Kern. C. W. Pitzer. R. M.: Karplus. M. I. Chem. Phus. 1968. 49.2592.

20. Conrad. R. M.: Dows. D. A. Spectrochim. Acta 1965. 21. 1039.

21. Servis. K. L.: Roberts. J. D. J.Am. Chent. Soc. 1965, 87. 1339.

22. Bach. A.: Lentz. D.; Luger. P.; Messerschmidt. M.: Olesch, C.; Patzschke. M. Angew. Chem. Int. Ed. 2002, H1, 296.

23. Jefìey. G. A. An horoduction to Hydrogen Bonding. Oxford University Press: New York. 1997: p 92.

24. Craig. N. C.: Neese. C. F.: Nguyen. T. N.: Oertel. C. M.: Pedraza. L.: Chaka, A. M. J. Phys Chent A 1999. 103.6726.

25. Becke. A. D. J. Chem. Phs 1993, 98,1372

26. Hu. H.-R; Tian, A.: Wong, N.-B.; Li, W.-K. J. Phys. Chent A 2001. 105.10372 